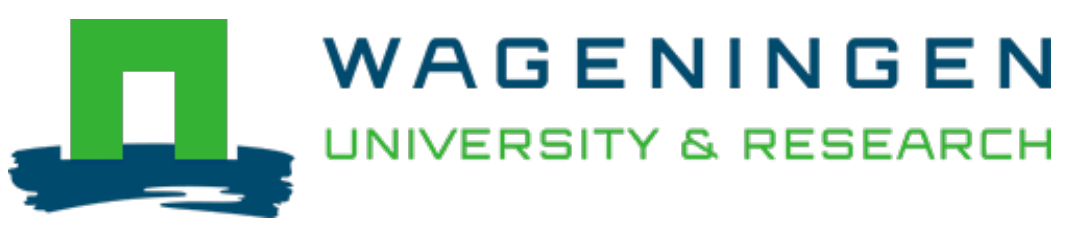

\title{
Intercropping cereals with faba bean reduces plant disease incidence regardless of fertilizer input; a meta-analysis
}

\author{
European Journal of Plant Pathology \\ Zhang, Chaochun; Dong, Yan; Tang, Li; Zheng, Yi; Makowski, David et al \\ https://doi.org/10.1007/s10658-019-01711-4
}

This publication is made publicly available in the institutional repository of Wageningen University and Research, under the terms of article $25 \mathrm{fa}$ of the Dutch Copyright Act, also known as the Amendment Taverne. This has been done with explicit consent by the author.

Article 25 fa states that the author of a short scientific work funded either wholly or partially by Dutch public funds is entitled to make that work publicly available for no consideration following a reasonable period of time after the work was first published, provided that clear reference is made to the source of the first publication of the work.

This publication is distributed under The Association of Universities in the Netherlands (VSNU) 'Article $25 \mathrm{fa}$ implementation' project. In this project research outputs of researchers employed by Dutch Universities that comply with the legal requirements of Article $25 \mathrm{fa}$ of the Dutch Copyright Act are distributed online and free of cost or other barriers in institutional repositories. Research outputs are distributed six months after their first online publication in the original published version and with proper attribution to the source of the original publication.

You are permitted to download and use the publication for personal purposes. All rights remain with the author(s) and / or copyright owner(s) of this work. Any use of the publication or parts of it other than authorised under article $25 \mathrm{fa}$ of the Dutch Copyright act is prohibited. Wageningen University \& Research and the author(s) of this publication shall not be held responsible or liable for any damages resulting from your (re)use of this publication.

For questions regarding the public availability of this publication please contact openscience.library@wur.nl 


\title{
Intercropping cereals with faba bean reduces plant disease incidence regardless of fertilizer input; a meta-analysis
}

\author{
Chaochun Zhang • Yan Dong • Li Tang • Yi Zheng • \\ David Makowski • Yang Yu • Fusuo Zhang • \\ Wopke van der Werf
}

Accepted: 7 March 2019

(C) Koninklijke Nederlandse Planteziektenkundige Vereniging 2019

\begin{abstract}
Ecological intensification of agriculture calls for ecological mechanisms to replace anthropogenic inputs. Cereal/legume intercropping increases yields due to species complementarities, it produces high protein food and feed, and it reduces the need for artificial $\mathrm{N}$ fertilizer because legumes fix $\mathrm{N}$ biologically. In addition, intercropping has the potential to suppress plant diseases, but its efficacy for disease suppression in
\end{abstract}

Chaochun Zhang and Yan Dong contributed equally to this work.

Electronic supplementary material The online version of this article (https://doi.org/10.1007/s10658-019-01711-4) contains supplementary material, which is available to authorized users.

C. Zhang $\cdot$ F. Zhang

College of Resources and Environmental Science, China

Agricultural University, Beijing, China

C. Zhang $(\bowtie)$

Center for Resources, Environment and Food Security, China

Agricultural University, 100193, No.2 Yuanmingyuan Xilu,

Haidian District, Beijing, China

e-mail: zhangcc@cau.edu.cn

Y. Dong $\cdot$ L. Tang $\cdot$ Y. Zheng

College of Resources and Environmental Science, Yunnan

Agricultural University, Yunnan Province, China

D. Makowski

INRA, UMR 211 Agronomie, INRA AgroParisTech Université

Paris_Saclay, 78850 Thiverval Grignon, France

Y. Yu • W. van der Werf

Centre for Crop Systems Analysis, Wageningen University,

P.O. Box 430, 6700 AKWageningen, The Netherlands cereal/legume mixtures has not been well characterized quantitatively. Here we conducted meta-analysis to quantify the disease suppressive effect of intercropping cereals with legumes at different levels of $\mathrm{N}$ fertilizer. Intercropping reduced disease incidence (measured by the odds ratio of disease occurrence) by $45 \%$ on average. This reduction was significant $(P<0.01)$ for four out of six studied pathogens: yellow rust (Puccinia striiformis f.sp. tritici) and mildew (Blumeria graminis) in wheat (Triticum aestivum), and chocolate spot (Botrytis fabae) and Fusarium wilt (Fusarium oxysporum) in faba bean (Vicia faba). Disease reduction was marginally significant for yellow rust in barley (Puccinia striiformis f.sp. hordei) $(P<0.10)$ and not significant for bean rust (Uromyces fabae). The reduction in disease incidence was greatest during the early stages of epidemics. $\mathrm{N}$ fertilizer strongly increased the incidence of powdery mildew of wheat, but it did not affect the incidence of the other diseases and it did not affect the effectiveness of intercropping as a management strategy for disease control. While nitrogen input increased powdery mildew incidence in both sole and intercropped wheat, the incidence was lower in the intercropped than sole wheat at all levels of $\mathrm{N}$ input. The disease suppressive effect of intercropping on wheat powdery mildew or any other disease was not affected by the amount of nitrogen fertilizer. The results show that intercropping has a substantial and consistent effect on disease incidence in cereal/faba bean mixtures across studies, but is not sufficient to provide complete disease control. Intercropping is therefore best used as a component in an integrated approach for managing plant diseases. 
Keywords Intercropping · Disease control $\cdot$ Metaanalysis $\cdot$ Nutrient management

\section{Introduction}

Pests and diseases are a major cause of crop losses, estimated at $10-16 \%$ of global agricultural productivity (Chakraborty and Newton 2011). Achieving effective control of pests and diseases is therefore important for food security (Wiik 2009; Savary et al. 2012). Diversification of crops at field and landscape level has been shown to suppress diseases, but the level of suppression varies substantially between studies (Zhu et al. 2000; Mitchell et al. 2003; Garrett et al. 2009; Turnbull and Hector 2010; Boudreau 2013). There is a need for quantitative synthesis to ascertain the extent to which crop diversity reduces disease, and assess the practical usefulness of this strategy in modern high input agricultural systems.

Intercropping is the cultivation of two or more crop species in the same field at the same time. Intercropping is used by smallholder farmers across the world to increase yield per unit area and reduce the risk of crop failure (Willey 1985; Vandermeer 1998; Zhang and Li 2003; Li et al. 2009; Martin-Guay et al. 2018). Intercropping has an average land equivalent ratio of slightly above 1.2 across the world, indicating that attaining the output of a unit area of intercrop would require 20\% more land if sole crops were used (Yu et al. 2015). Thus, adoption of intercropping provides substantial land savings (Martin-Guay et al. 2018). Moreover, intercropping can improve soil quality (Cong et al. 2015) and it suppresses diseases (Trenbath 1993; Zhu et al. 2000; Boudreau 2013) and pests (Tooker and Frank 2012). Intercropping provides a possible pathway for ecological intensification, i.e. achieving high crop yields and improving the environment by using ecological mechanisms to reduce anthropogenic inputs in agriculture (Bommarco et al. 2013).

In practical intercropping, smallholder farmers usually combine crop species with complementary growth patterns and patterns of resource requirement over time or space (Lithourgidis et al. 2011). However, reductions in plant diseases and pests have been recorded also for variety mixtures, i.e. through intra-specific diversity (Zhu et al. 2000; Tooker and Frank 2012). Zhu et al. (2000) reported 94\% reduction in plant disease in intercropping of two rice genotypes in Yunnan. Other studies on intercropping for disease control have usually achieved lower rates of disease suppression, but experiments assessing the plant disease reducing effect of species mixtures have never been synthetized quantitatively through meta-analysis to provide an overarching analysis. There is a need for critical analysis of literature to synthesize the existing knowledge and ascertain the average levels of disease reduction attained in intercropping, its variability across studies, and factors affecting disease suppression.

Mixtures of cereals and legumes are widely used in traditional smallholder agriculture (Zhang and Li 2003) and they also attract interest in modern agriculture because they can reduce the need for synthetic nitrogen fertilizer input in farming systems (Pelzer et al. 2012; Bedoussac et al. 2015). The majority of studies on yield increase by intercropping have been done using mixtures of cereals and legumes (Yu et al. 2016) and disease suppression has also been most widely studied for cereal/legume mixtures (Boudreau 2013).

Cereal/faba bean mixtures are widely cultivated for food in southern China, particularly in the province of Yunnan where many studies on disease suppression by intercropping have been conducted over the last 20 years (Chen et al. 2007; Li et al. 2009). However, no synthesis has been made of the data in these studies, and their results are largely not available in the international literature because the original sources are in Chinese. Most of the studies on disease control by intercropping in Yunnan include nitrogen treatments to test the hypothesis that high rates of nitrogen fertilizer would increase plant disease and reduce the effectiveness of intercropping for disease control. Intensive farming relies largely on nitrogen fertilizer, and there is increasing concern on the fact that overuse nitrogen may exaggerate the yield losses due to the enhanced disease severity (Lv et al. 2005; Zhang et al. 2008), and thus increase the use of pesticides (Tilman et al. 2002). Analysing the interaction between the effects of intercropping and $\mathrm{N}$ fertilizer on plant disease is therefore pertinent. Very little work on these interactions has been published in English, but there is a substantial body of knowledge in the Chinese literature, particularly from the southern province of Yunnan, where intercropping is actively used by farmers (Hong et al. 2017).

Here, we synthesize the published information on disease suppression by intercropping in cereal/faba 
bean mixtures in Yunnan. We quantify the effect of intercropping on important wheat diseases caused by Puccinia striiformis f. sp. tritici and Blumeria graminis, and in barley by Puccinia striiformis $\mathrm{f}$. sp. hordei, as well as three major pathogens in field bean: Botrytis fabae, Uromyces fabae and Fusarium oxysporum f. sp. fabae. The results demonstrate large and consistent reductions in disease incidence across pathogen taxa, including three aerially spread plant pathogens (rusts and mildew), but also a soilborne pathogen (Fusarium).

\section{Methods}

Data collection

A literature search was performed in Web of Science Core Collection and the China National Knowledge Infrastructure (CNKI) using the terms "disease", "intercropping", "nitrogen fertilizer" or "N fertilizer", in various combinations in the fields for title, keywords and abstract. The search was originally done in 2010 and updated in May, 2018. We excluded review papers, studies without replicates, studies without quantitative data on disease incidence, or studies that did not report the rate of $\mathrm{N}$ fertilizer. The search resulted in 26 publications on a variety of systems, but with a dominance of cereal/legume mixtures. To reduce heterogeneity in the data, and because of the expected environmental benefit of an integration of legumes in cropping systems, we focused the current analysis on cereal/legume mixtures. The resulting dataset included 17 publications (supplement S2). It comprised seven peer-reviewed publications, two book chapters, and eight MSc and $\mathrm{PhD}$ theses (all in Chinese). Some publications reported the results of several experiments, and the total number of experiments was equal to 46. All selected publications turned out to be studies conducted in the province Yunnan in China (this was not a selection criterion but an outcome). Yunnan province is located in the southwest of China, and the high humidity in the region favours diseases. Many intercropping studies were conducted in this province following the work of Zhu et al. (2000) that showed the suppressive of effect of rice variety mixtures on rice blast. The suppressive effect of cereal/legume intercropping was rarely studied in other Chinese regions such as the Northwest of China, due to their semi-arid conditions unfavourable for disease (Zhang and Li 2003).

In our dataset, cereal crops were wheat (Triticum aestivum) or barley (Hordeum vulgare) (in two of the 26 papers), and the legume crop was in all instances faba bean (Vicia faba); these species are grown in most cereal/legume intercropping systems in Yunnan province. All the selected studies shared several common experimental design characteristics (supplement S3). In short, each experiment included three treatments: a sole cereal (wheat or barley), a sole faba bean, and an intercrop of these species. The most common intercrop configuration comprised an alternation of a cereal strip consisting of six rows and a faba bean strip consisting of two rows (Fig. S4, S5). This configuration is also common amongst local farmers. In all publications, plot sizes varied from 30 to $200 \mathrm{~m}^{2}$. In 37 out of 46 experiments, disease observation data were collected in three replicate plots. In all other experiments, the number of replicates was unknown but always equal to or higher than three. The number of nitrogen fertilizer levels was three or four, including in most cases an unfertilized treatment, conventional fertilizer amount (varying among studies), a reduced rate (often $50 \%$ of conventional) and an increased rate (often $150 \%$ of conventional). No fungicides or insecticides were used in any of the experiments.

\section{Disease incidence}

Disease incidence was determined at five random positions in each plot (approximately in an X pattern across the plot) (Fig. S6) and at each sampling position the diseases were recorded on three faba bean plants or on one wheat or barley plant. In experiments including three replicates, each disease incidence observation was thus derived from a total of $3 \times 5 \times 3=45$ faba bean plants or $3 \times 5=15$ bunches of wheat or barley. All leaves of the observed plants were inspected to score disease presence or absence. Disease incidence $(I)$ was calculated at the replicate level as the number of infected leaves in the plot divided by the number of surveyed leaves in the plot, and then averaged over replicates. In the case of 
Fusarium wilt, 30 plants per plot were scored, and the presence of wilting symptoms on the plant was recorded. Dates of disease observation were classified in three time periods: early season when disease symptoms just start to be detectable, midseason, 20 days after the first observation when disease incidence is rapidly increasing, and late season, 20 days after the second observation. Disease observation times were tailored to the different pathogens, depending on their dates of the first appearance in the field (Supplement S3).

Disease incidence data were converted to logits for further analysis (Agresti 2002; Zadoks and Schein 1979), $y$ :

$y=\operatorname{logit}(x / 100)=\ln \left(\frac{x}{100-x}\right)$

where $x$ is disease incidence (proportion, in \%), $x$ / $(100-x)$ are the "odds" of disease incidence (i.e. the ratio of the proportion of infected leaves to the proportion of healthy leaves), and $y$ is the logit of disease incidence. The logit is the natural logarithm of the Odds (here, the Odds of disease occurrence). This function is commonly used to transform variables taking values in the range $0-1$ (e.g., proportions computed from binomial data). Such variables cannot be directly related to a linear model because a linear combination of covariates can take any real value, and there is no guarantee that the values predicted by the linear model will be in the range $0-1$. The logit function maps proportions from the range $(0,1)$ to the entire real line. Thus, the logit transformation removes the $0-1$ range restriction, and the transformed data can then be directly related to any linear combination of covariates. Logits are back-transformed to incidence $(\%)$ as $x=\frac{100 \times e^{y}}{1+e^{y}}$. Incidence observations equal to 0 or 100 were set equal to 0.1 and 99.9 , respectively, to avoid singularities when calculating logits.

The collected publications contained data on six diseases, two of them infecting wheat (powdery mildew, Blumeria graminis (DC.) Speer, and yellow rust, Puccinia striiformis f. sp. tritici), one infecting barley (yellow rust, Puccinia striiformis f. sp. hordei), and three of them infecting faba bean (chocolate spot, Botrytis fabae, bean rust, Uromyces fabae, and Fusarium wilt, Fusarium oxysporum f. sp. fabae).

\section{Disease control effectiveness}

Within each block, we calculated the difference in $y$ between the plants of a given species in intercrop plots and those in the sole crop plots:

$$
\begin{aligned}
\Delta y=\operatorname{logit}\left(x_{I C} / 100\right)-\operatorname{logit}\left(x_{M} / 100\right) & =\ln \left(\frac{x_{\mathrm{IC}}}{100-x_{\mathrm{IC}}}\right)-\ln \left(\frac{x_{\mathrm{M}}}{100-x_{\mathrm{M}}}\right) \\
& =\ln \left(\frac{\left(\frac{x_{\mathrm{IC}}}{100-x_{\mathrm{IC}}}\right)}{\left(\frac{x_{\mathrm{M}}}{100-x_{\mathrm{M}}}\right)}\right)
\end{aligned}
$$

where $x_{\mathrm{IC}}$ is disease incidence in the intercrop and $x_{\mathrm{M}}$ is disease incidence in the sole crop.

$\Delta y$ is also known as the log of the odds ratio (Agresti 2002; Borenstein et al. 2009). The log odds ratio is frequently used in meta-analysis when the data represent proportions of diseased individuals (Borenstein et al. 2009). Analyses of the disease control effect of intercropping were conducted using $\Delta y$ as response variable. The disease control effectiveness (CE) was calculated from $\Delta y$ as $\mathrm{CE}=100(1$ $\left.-\mathrm{e}^{\Delta y}\right)$, where $\mathrm{e}^{\Delta y}$ is the ratio of the odds of disease in the intercrop versus the sole crop. Positive values of $\mathrm{CE}$ indicate that intercropping reduces relative disease risk, while negative values indicate that intercropping increases relative risk. As all the considered diseases are specific to either the cereal or the legume species, disease in only one of the sole crops was considered as a reference to calculate $\Delta y$.

Explanatory variables and statistical analysis

$\Delta y$ was analysed using linear mixed effects models (Table 1), considering three explanatory variables (Table S1): pathogen species (categorical with six levels), observation time (categorical with three levels), fertilizer level (categorical with four levels) and $\mathrm{N}$ dose. Seven linear mixed effects models were formulated (Table 1). All seven models included nested random effects reflecting the effects of factors associated with publications, and within publication the effect of study (site $\times$ year) (Pinheiro and Bates 2000; Zuur et al. 2009; Yu et al. 2015). The optimal random effects structure (publication and study as nested random effects) was identified using Akaike's Information Criterion (Zuur et al. 2009). A Box-Cox transformation was applied to normalize $\Delta y$ and an optimal exponent for this transformation was selected using the 
Table 1 Mixed-effect models fitted to analyse relationship between log disease odds ratio and pathogen species, time of observation, and $\mathrm{N}$ fertilizer

\begin{tabular}{ll}
\hline Model & Equation \\
\hline 1 & $\Delta y_{i j k}=\beta_{0}+\mathrm{a}_{i}+\mathrm{b}_{i j}+\epsilon_{i j k}$ \\
2 & $\Delta y_{i j k}=\beta_{\text {time }}\left(\right.$ time $\left._{i j k}\right)+\mathrm{a}_{i}+\mathrm{b}_{i j}+\epsilon_{i j k}$ \\
3 & $\Delta y_{i j k}=\beta_{\text {disease }}\left(\right.$ disease $\left._{i j k}\right)+\mathrm{a}_{i}+\mathrm{b}_{i j}+\epsilon_{i j k}$ \\
4 & $\Delta y_{i j k}=\beta_{\text {disease }}\left(\right.$ disease $\left._{i j k}\right)+\beta_{\text {time }}\left(\right.$ time $\left._{i j k}\right)+\mathrm{a}_{i}+\mathrm{b}_{i j}+\epsilon_{i j k}$ \\
5 & $\Delta y_{i j k}=\beta_{\text {NlevelCereal }}\left(\right.$ NlevelCereal $\left._{i j k}\right)+\mathrm{a}_{i}+\mathrm{b}_{i j}+\epsilon_{i j k}$ \\
6 & $\Delta y_{i j k}=\beta_{\text {NlevelLegume }}\left(\right.$ NlevelLegume $\left._{i j k}\right)+\mathrm{a}_{i}+\mathrm{b}_{i j}+\epsilon_{i j k}$ \\
7 & $\Delta y_{i j k}=\beta_{\text {Ntotal }} N_{\text {total } i j k}+\mathrm{a}_{i}+\mathrm{b}_{i j}+\epsilon_{i j k}$
\end{tabular}

(Seven models were fitted to data. All are mixed effects models accounting for fixed effects (disease, time of observation, $\mathrm{N}$ fertilizer) and random effects (publication, study (disease) within publication, and multiple observations within studies). Model 1 was used to describe the mean and variability of log disease odds ratio between intercropping and sole cropping (Fig. 1). Model 2 was used to describe differences between observation times in the effect of intercropping (Fig. S1). Here $\beta_{\text {time }}\left(\right.$ time $_{i j k}$ ) can take three values, depending on the time of observation. The values describe the average effect of intercropping on disease incidence at three times of observation (early, middle or late). Model 3 was used to describe the overall effect of intercropping on six different diseases (Fig. 2d). Here $\beta_{\text {disease }}$ (disease $e_{i j k}$ ) describes the average effect of intercropping on the incidence of each of six diseases (wheat powdery mildew (WPM), wheat yellow rust (WR), barley rust (BR), faba bean chocolate spot (FBLP), faba bean rust (FBR), faba bean wilt (FBW)). Model 4 was used to describe the effect of intercropping on six diseases at three different observation times (Fig. 2a-c). Here $\beta_{\text {disease }}\left(\right.$ disease $\left._{i j k}\right)$ and $\beta_{\text {time }}\left(\right.$ time $\left._{i j k}\right)$ are the vectors with the same meanings of those in the Model 3 and the Model 2 , respectively. Model 5 was used to describe the effect of intercropping on four levels of nitrogen fertilizer applied to the cereal strip (Fig. 3a), while model 6 does the same for fertilizer applied to the legume (Fig. 3b). Here $\beta_{\text {NlevelCereal }}$ (NlevelCereal ${ }_{i j k}$ ) or $\beta_{\text {NlevelLegume }}$ (NlevelLegume $i j k$ ) is the vector with four elements representing the average effect of intercropping on the incidence at each of four $\mathrm{N}$ levels (no $\mathrm{N}$ application, half of the optimal $\mathrm{N}$ level, $\mathrm{N}$ dose recommended in practice, $\mathrm{N}$ dose $50 \%$ higher than the recommended dose) given cereal or legume crop, respectively. Model 7 was used to describe the effect of intercropping varying with $\mathrm{N}$ dosage. The indices $i, j$, and $k$ represent publication ID, study ID and observation number, respectively. Study refers to the combination of crop species and disease within the publication. In all mixed effect models, $\mathrm{a}_{i}$ is a random publication effect; $\mathrm{b}_{i j}$ is a random study effect nested within the $i^{\text {th }}$ publication. Both $a_{i}$ and $\mathrm{b}_{i j}$ are assumed normally distributed with constant variances. $\varepsilon_{i j k}$ is a residual random error assumed normally distributed with constant variance. The variance terms, $\mathrm{a}_{i}, \mathrm{~b}_{i j}$ and $\varepsilon_{i j k}$ were all assumed independent)

Shapiro test (Royston 1982). The normality of the residuals of the selected model was checked graphically (Fig. S7) (Zuur et al. 2009).
To study the effect of intercropping and $\mathrm{N}$ input on disease incidence, we analysed the logit-transformed disease incidence $(y)$. This variable was related to three explanatory variables using three linear mixed regression models including $\mathrm{N}$ fertilizer dosage, cropping system (categorical with two levels) and observation time (categorical with three levels) as independent variables (Table 2). All these four models were optimally structured with respect to random effects as described for models for $\Delta y$. Furthermore, the logit-transformed disease incidence $(y)$ was further optimized for analysis by applying the Box-Cox transformation to normalize $y$ (Royston 1982). The optimal exponent for this transformation was found by maximizing the $P$ value of Shapiro's test for departure from normality of residuals. The normality of the residuals of the selected model was checked graphically (Fig. S8).

All analyses were performed in R ( R Core Team, 2015) using the $R$ function lme for fitting linear mixed effects models (R package nlme; Pinheiro and Bates 2000).

Table 2 Mixed-effect models fitted to analyse relationship between $\log$ disease odds and $\mathrm{N}$ dose and cropping systems

\begin{tabular}{ll}
\hline Model & Equation \\
\hline 1 & $y_{i j k}=\beta_{0} N_{\text {total } i j k}+\mathrm{a}_{i}+\mathrm{b}_{i j}+\epsilon_{i j k}$ \\
2 & $y_{i j k}=\beta_{\mathrm{CS}}\left(C S_{i j k}\right)+\beta_{\text {Ntotal }} N_{\text {total } i j k}+\mathrm{a}_{i}+\mathrm{b}_{i j}+\epsilon_{i j k}$ \\
3 & $y_{i j k}=\beta_{\mathrm{CS}}\left(C S_{i j k}\right)+\beta_{\text {NCereal }} N_{\text {Cereal } i j k}+\mathrm{a}_{i}+\mathrm{b}_{i j}+\epsilon_{i j k}$ \\
4 & $y_{i j k}=\beta_{\mathrm{CS}}\left(C S_{i j k}\right)+\beta_{\text {NLegume }} N_{\text {legume } i j k}+\mathrm{a}_{i}+\mathrm{b}_{i j}+\epsilon_{i j k}$ \\
\hline
\end{tabular}

(Four models were fitted to data. All are mixed effects models accounting for fixed effects (cropping system and $\mathrm{N}$ fertilizer) and random effects (publication, study (disease) within publication, and multiple observations within studies). Model 1 was used to describe overall effect of nitrogen rate on log disease odds. Model 2 was used to describe a regression of $\log$ disease odds against nitrogen dosage in two cropping systems across all times (Fig. S2) or at each observation time (Fig. S3). Here $\beta_{\mathrm{CS}}\left(C S_{i j k}\right)$ describes the $\log$ disease odds of two cropping systems (intercropping and sole cropping). Model 3 or Model 4 was used to describe the regression of $\log$ disease odds in two cropping systems against nitrogen dosage given specifically to cereal in the cereal strip (Fig. 4a, b), or $\mathrm{N}$ given to the legume in the legume strip (Fig. 4c), respectively. The indices $i, j$, and $k$ represent publication ID, study ID and observation number, respectively. Study refers to the combination of crop species and disease within the Publication. In all mixed effect models, $\mathrm{a}_{i}$ is a random publication effect; $\mathrm{b}_{i j}$ is a random study effect nested within the $i^{\text {th }}$ publication. Both $\mathrm{a}_{i}$ and $\mathrm{b}_{i j}$ are assumed normally distributed with constant variances. $\varepsilon_{i j k}$ is a residual random error assumed normally distributed with constant variance. The variance terms, $\mathrm{a}_{i}, \mathrm{~b}_{i j}$ and $\varepsilon_{i j k}$ were all assumed independent) 


\section{Results}

Disease control effectiveness of the intercropping

The disease odds ratio in the intercrop and the sole crop was measured with the equation: $\frac{x_{\mathrm{IC}}}{100-x_{\mathrm{IC}}} / \frac{x_{\mathrm{M}}}{100-x_{\mathrm{M}}}$, where $x_{\mathrm{IC}}$ is the measured incidence of disease in the intercrop and $x_{\mathrm{M}}$ is the measured incidence of disease in the sole crop (IC for intercropping and $\mathrm{M}$ for Sole crop) (Fig. 1). The median log of the disease odds ratio was equal to -0.60 and was highly variable over studies, experiments within studies, and treatments within experiments (Fig. 1; model 1 in Table 1). About $75 \%$ of the log odds ratios were negative, and this result indicated that disease incidence is reduced in intercropping in most cases, and intercropping gave an average reduction in relative disease risk of $\mathrm{CE}=45 \%$ (Fig. 1).

The effect of intercropping on disease incidence varied over the season (model 2; Table 1 Fig. S1), with a greater control effect during early $\left(\Delta y=\beta_{\text {time }}(e a r l y)=-\right.$ $0.407, \mathrm{CE}=33 \%, P<0.001$; model 2 ; Table 1 ) and midseason $\left(\Delta y=\beta_{\text {time }}(\right.$ mid $)=-0.305, \mathrm{CE}=26 \%, P<0.001$; model 2; Table 1) than during late season $(\Delta y$ $=\beta_{\text {time }}($ late $)=-0.118, \mathrm{CE}=11 \%, P=0.055 ;$ model 2 ;
Table 1) (Fig. 2). Intercropping reduced the odds of yellow rust of wheat by $28 \%\left(\Delta y=\beta_{\text {disease }}(W R)=-\right.$ $0.332, P<0.001$; model 3; Table 1$)$ and of powdery mildew of wheat by $21 \%\left(\Delta y=\beta_{\text {time }}(W P M)=-0.240\right.$, $P=0.008$; model 3; Table 1) according to the mean estimates obtained from the fitted mixed-effect models (Fig. 2). The meta-analysis demonstrated no significant effect of intercropping on barley rust $(P=0.508)$, possibly due to the small number of studies with barley as the cereal. A $31 \%$ reduction in the odds of disease was observed for chocolate spot of faba bean $(\Delta y$ $=\beta_{\text {disease }}(F B L P)=-0.376, P<0.001 ;$ model $3 ;$ Table 1$)$ and a large (39\%) but only marginally significant effect on bean rust $\left(\triangle y=\beta_{\text {disease }}(F B R)=-0.488, P=0.080\right.$; model 3; Table 1). Intercropping reduced the odds of Fusarium wilt in faba bean by $72 \%\left(\Delta y=\beta_{\text {disease }}(F B W)=\right.$ $-1.28, P<0.001$; model 3; Table 1).

For none of the six diseases did we find an effect of $\mathrm{N}$ fertilizer rate on the control effectiveness of intercropping (Fig. 3; models 5 and 6; Table 1). N input dosage did not significantly affect the control effectiveness (CE) across all diseases $(P=0.478$; model 7; Table 1), and neither influenced the CE of any of the six diseases $(P=0.759$ for wheat powdery mildew, $P=0.277$ for wheat yellow rust,
Fig. 1 Frequency distribution of the relative odds of disease in intercropping as compared to sole cropping, using 351 data records, originating from 46 experiments on the effects of intercropping on plant diseases as a function of nitrogen level, and 86 crop species-pathogen combinations within experiments (i.e. on average 1.87 crop species-pathogen per experiment). Horizontal axis represents $(\Delta y)$, i.e. the log of the disease odds ratio, or - equivalently - the difference in logit of incidence of disease in the intercrop and the sole crop (Eq. 1). Vertical lines indicate the first quartile (Q1), median and the third (Q3) quartile of the intercropping effect. CE is the control effectiveness of intercropping, calculated as $\mathrm{CE}=$ $100\left(1-e^{\Delta y}\right)$

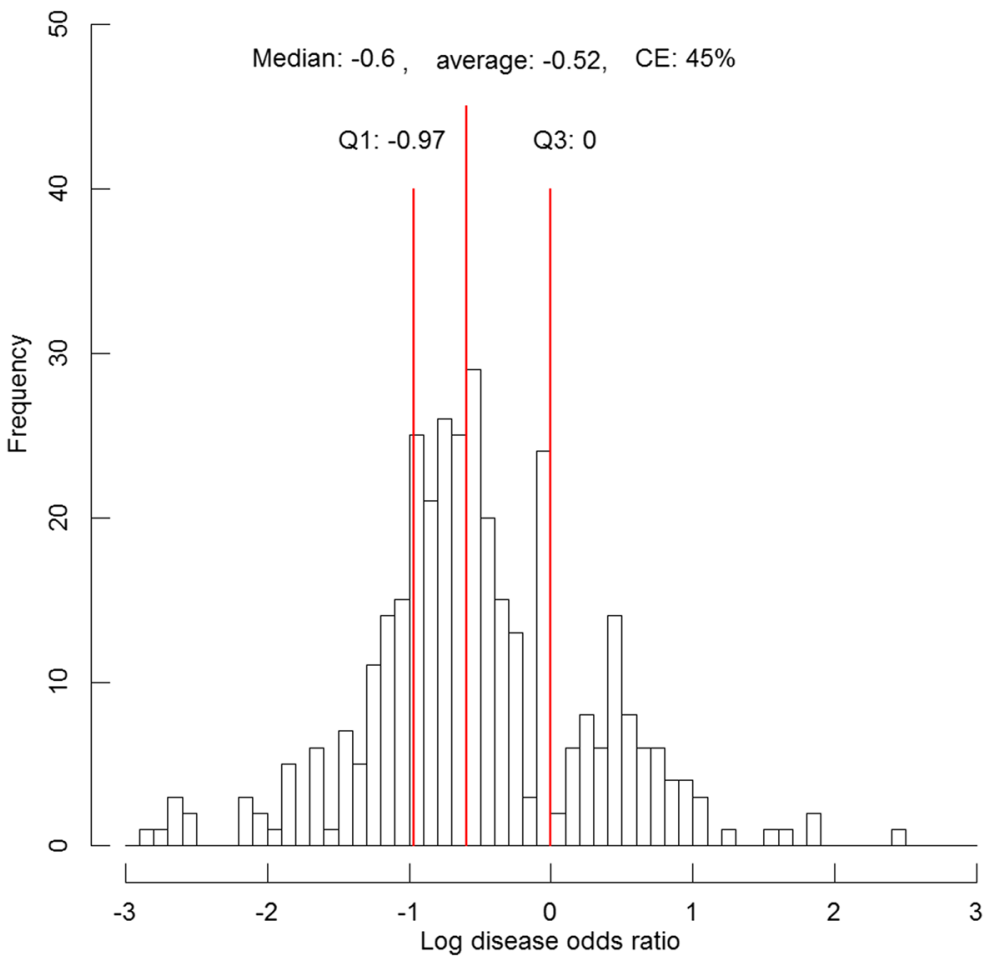



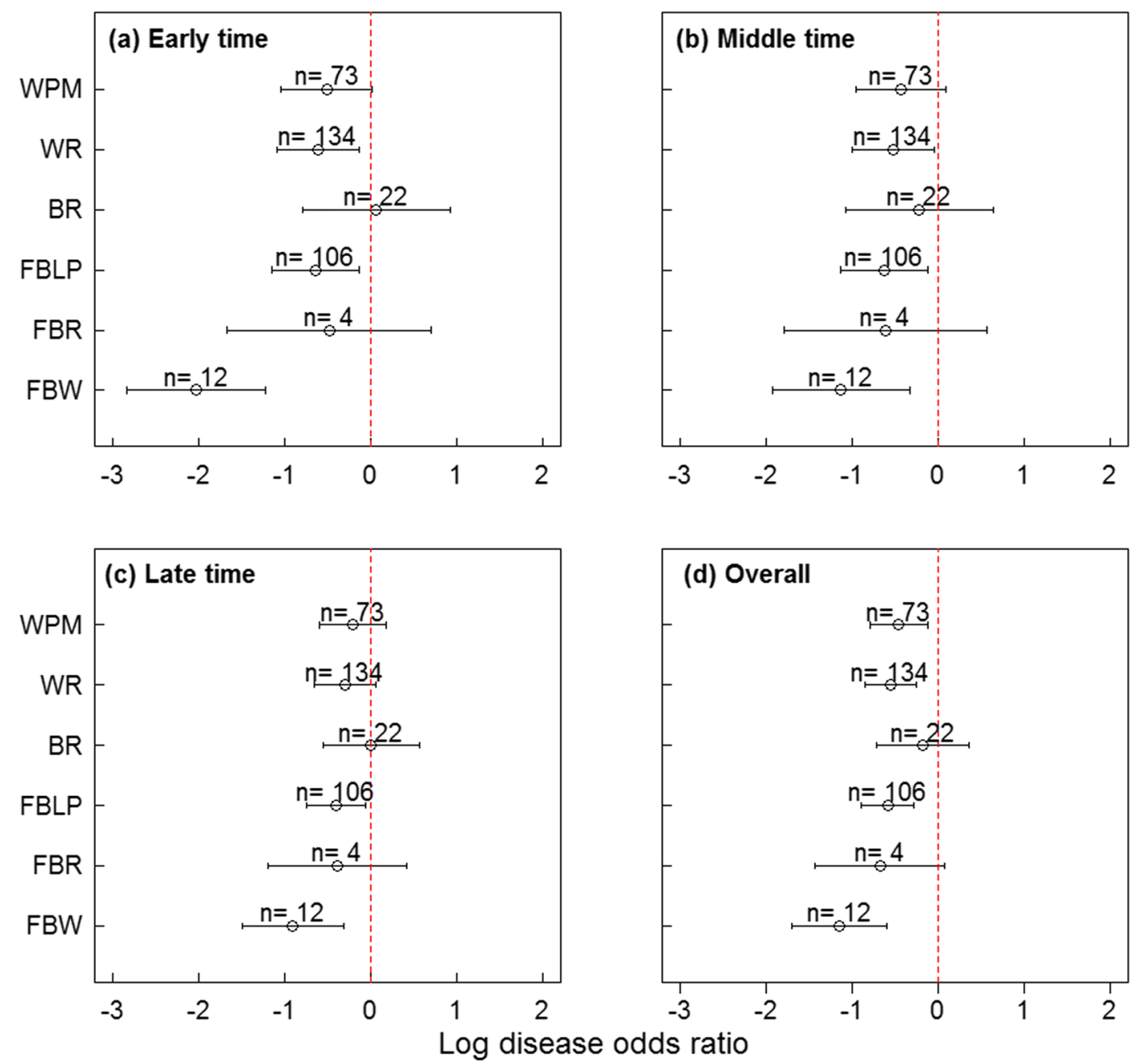

Fig. 2 Relative incidence of disease in intercropping as compared to sole crop for six plant diseases and during three phases of the epidemic: early (a), mid (b) and late (c) and overall (d). Abbreviations for diseases: WPM: wheat powdery mildew (Blumeria graminis (DC.) Speer); WR: wheat yellow rust (Puccinia striiformis f. sp. tritici); BR: barley rust (Puccinia strifformis west f. sp. hordei); FBLP: faba bean chocolate spot (Botrytis fabae);

$P=0.280$ for barley rust, $P=0.581$ for faba bean chocolate spot, $P=0.888$ for faba bean rust, and $P=0.914$ for faba bean wilt). We therefore conclude that intercropping suppresses plant disease consistently across dosages of $\mathrm{N}$ fertilizer.

Disease incidence affected by intercropping and nitrogen

Plant disease incidence increased significantly with $\mathrm{N}$ fertilizer input $(P=0.014$; model 1 ; Table 2$)$, with a marginal effect on intercrops but no effect on sole
FBR: faba bean rust (Uromyces viciae fabae); FBW: faba bean Fusarium wilt (Fusarium oxysporum f. sp. fabae). Times of observation are detailed in Supplementary materials S2. Horizontal axis $(\Delta y)$ represents the log of the disease odds ratio, i.e. the difference in logit (incidence) in the intercrop and the control treatment (sole crop) (Eq. 2). Error bars represent $95 \%$ confidence intervals. $n$ indicates the number of records in the database for a given disease

crops (Fig. S2; model 1; Table 2). The effect of $\mathrm{N}$ dose on disease incidence differed with the time of survey (Fig. S3; model 1; Table 2). Disease incidence at the mid time increased significantly with $\mathrm{N}$ fertilizer, but the incidences at both early and late observation times were not significantly affected by $\mathrm{N}$ fertilizer input. Higher doses of $\mathrm{N}$ fertilizer significantly increased wheat Powdery Mildew incidence in both sole crops and intercrops (Fig. 4a; model 2; Table 2), but $\mathrm{N}$ fertilizer did not influence the incidence of other diseases (Fig. 4b, c; models 3 and 4; Table 2). 
Fig. 3 Relative incidence of disease in intercropping as compared to sole crop at four levels of nitrogen fertilizer input: N0, no nitrogen; N1, half the recommended rate; $\mathrm{N} 2$, recommended rate; $\mathrm{N} 3$, recommended rate $+50 \%$. Horizontal axis $(\Delta y)$ represents the log disease odds ratio, i.e. the difference in logit(incidence) in the intercrop and the control treatment (sole crop) (Eq. 2). Error bars represent $95 \%$ confidence intervals. $n$ indicates the number of records in the database for a given disease
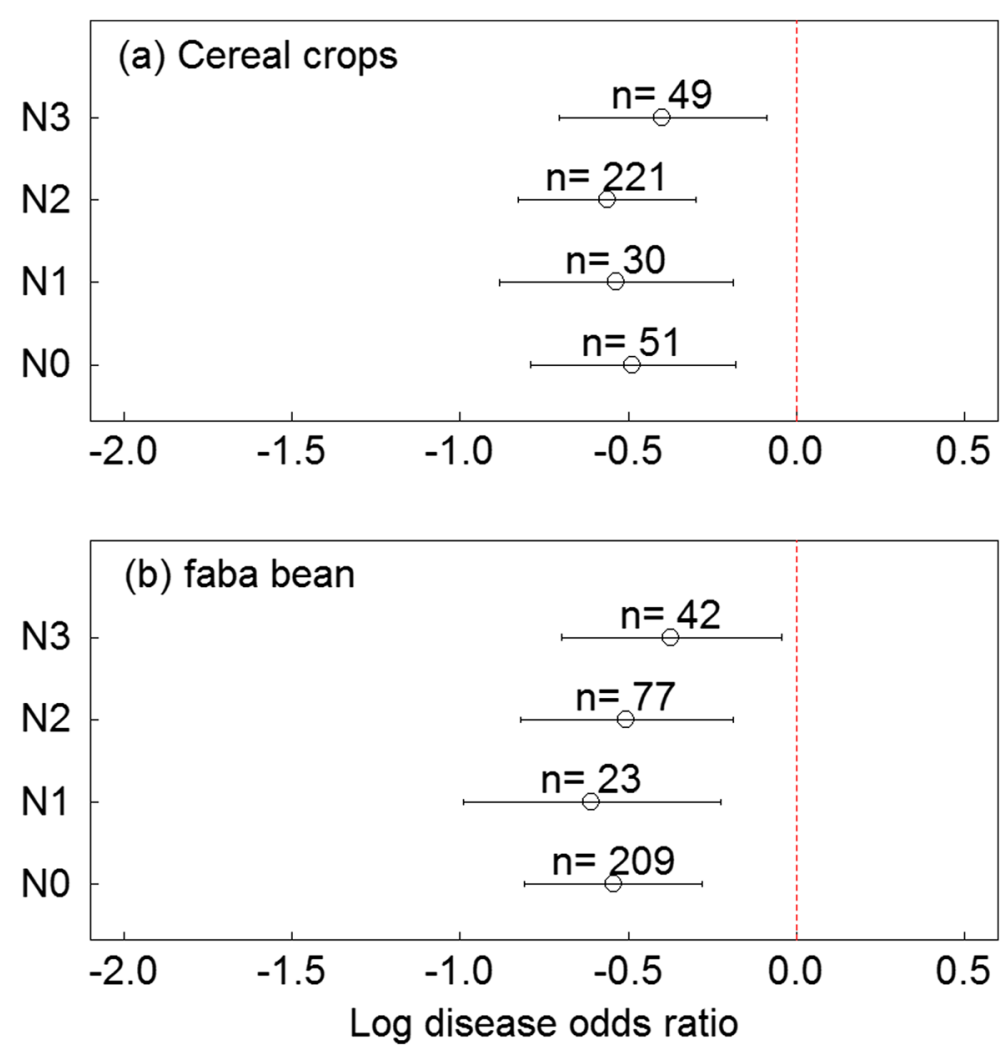

\section{Discussion}

Results of this meta-analysis show that intercropping consistently and substantially suppresses plant diseases. The overall average disease reduction was $33 \%( \pm 4 \%)$. The level of disease suppression varied between pathogens. The average control effect was $34 \%( \pm 7 \%)$ for P. striiformis in wheat, $20 \%( \pm 9 \%)$ for $B$. graminis in wheat, and insignificant for $P$. striiformis in barley. Control effectiveness in field bean was $39 \%( \pm 7 \%)$ for B. fabae, $36 \%( \pm 27 \%)$ for $U$. fabae, and $51 \%( \pm 21 \%)$ for $F$. oxysporum. The first five diseases are caused by air-borne obligate pathogens, and the last one is induced by a soil-borne facultative pathogen. The evidence confirms that greater host functional divergence, as the result of intercropping, leads to disease reduction (Mitchell et al. 2003; Garrett et al. 2009; Keesing et al. 2010; Dassou and Tixier 2016). Although the disease reduction levels reported here are both statistically significant and biologically relevant, they do not lead to a complete control of the diseases. This indicates that intercropping may not be suitable as a standalone solution, but it could well be used in an integrated pest management approach in which it may be combined with other management techniques such disease resistant cultivars, sanitation measures, diversified rotations, and fungicides.

Boudreau (2013) lists five mechanisms for disease suppression by intercropping: (1) interference with spore dispersal by wind or rain (as related to barrier effects of companion crops and host dilution in space), (2) interference with vectoring of disease, (3) alterations in micro-climate, (4) changes in host physiology and resistance, and (5) direct pathogen inhibition. Four of the five diseases that showed suppression in intercrops in this meta-analysis are dispersed by air, and it is highly plausible that host dilution in intercrops in these cases reduced the efficiency of spore deposition on hosts and the rate of spread of disease. This explanation is consistent with the greater reductions during early season, as a slower epidemic (resulting from lower dispersal efficacy) can catch up with a faster epidemic in later season (Skelsey et al. 2005). Results of this study are difficult to reconcile with a possible role for altered microclimate. All of the studied pathogens except $F$. oxysporum require leaf wetness for spore 
Fig. 4 Effect of nitrogen fertilizer on plant disease incidence on sole and intercropped wheat and faba bean. Green symbols show disease incidence (logit values; Eq. 1) in sole crops while red symbols show disease incidence on the same species in an intercrop. Panel A shows a strong and highly significant increase in the incidence of powdery mildew (Blumeria graminis) in sole and intercropped wheat. Panel B shows absence of a significant effect of nitrogen fertilizer on the incidence of yellow rust in wheat (WR; Puccinia striiformis f.sp. tritici) and yellow rust in barley (BR; Puccinia striiformis f.sp. hordei). Panel $\mathrm{C}$ shows absence of a significant effect of nitrogen fertilizer on three diseases in faba bean: leaf spot (FBLP; Botrytis fabae), rust (FBR; Uromyces fabae) and wilt (FBW; Fusarium oxysporum f.sp. fabae). In all three panels, there was a significant effect of intercropping on the intercept $(P<0.05)$ while there was no significant effect on the slope. Only B. graminis responded to nitrogen level. Fitted models have a common slope (after testing for difference in slope between sole cropping and intercropping, which was in all cases not significant)

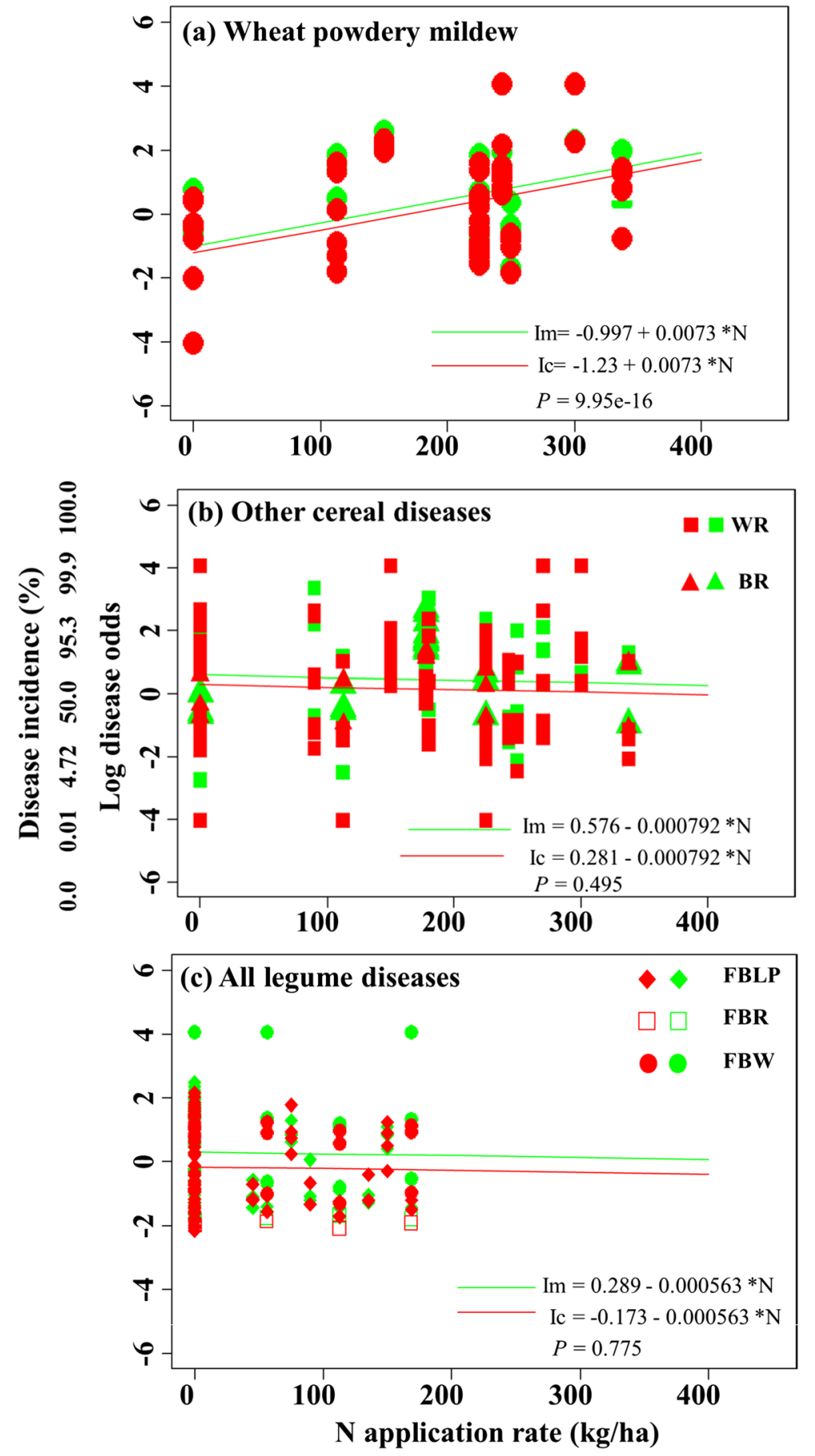

germination and infection. It is difficult to see how mixing a cereal with field bean would lower leaf wetness in both species. Hence, it seems not so likely that changed microclimate plays a role. The studied diseases are not vectored, and hence interference with vectors is not involved. Direct inhibition seems also unlikely for the aerially dispersed pathogens. Alterations in host physiology and resistance cannot be completely ruled out; however, this hypothesis does not need to be invoked because the level of disease suppression by intercropping in this meta-analysis is consistent with 
levels of disease suppression that have been found in models of plant disease epidemics in mixtures that take into account only the host dilution effect (Mundt 2002; Skelsey et al. 2005). Hence, the explanation for intercropping effect on plant disease that is most plausible for the aerially spread pathogens in this meta-analysis is the host dilution effect.

Fusarium wilt in faba bean is a soil-borne disease. Intercropping had greater control effectiveness on this disease than on the five aerially dispersed pathogens (Fig. 2d). Evidence is accumulating that soilborne diseases can be affected by biotic interactions in the rhizosphere that are driven by root exudates (Ren et al. 2008; Philippot et al. 2013; Xu et al. 2015; Jiang et al. 2017). Root exudates contain an array of primary and secondary plant metabolites that can attract, deter, or kill belowground microbes (Weston and Mathesius 2013; Strehmel et al. 2014; van Dam and Bouwmeester 2016). A recent study showed that plants roots excrete lipids that promote the growth of mycorrhizal and plant pathogenic fungi (Jiang et al. 2017). Thus, the working mechanisms of intercropping might differ fundamentally between aerially dispersed pathogens and pathogens that affect the below-ground plant parts.

Nitrogen fertilizer is commonly regarded as a key force driving disease occurence due to its effect on plant nutritional status and the suitability of the plant for pathogen multiplication (Hoffland et al. 1999; Snoeijers et al. 2000; Dordas 2008). Additionally, greater $\mathrm{N}$ application may cause a denser canopy, which results in a more favorable microclimate for infection (Jensen and Munk 1997; Simón et al. 2003; Neumann et al. 2004). In this data-set, nitrogen affected only the incidence of powdery mildew in wheat, and the incidence of other diseases was not affected. Here we found that intercropping was an effective disease suppressive measure for five out of six considered pathogens at all $\mathrm{N}$ fertilization levels, indicating that the disease suppressive effect may be exploited in high input agriculture.

Knowing the extent to which intercropping reduces disease is critical for end-users to raise interest in this ecological approach for disease management and to reduce where possible reliance on chemical pesticides. Our quantitative synthesis of experiments under smallholder conditions with zero fungicide input in cereal/ legume systems provides strong evidence of the suppressive effect of intercropping, and demonstrates the interest of including this approach within an integrated pest management framework.

Acknowledgments We are grateful for the financial support from the key project of the Ministry of Science and Technology of China (grant number 2016YFE0101100), the National Natural Science Foundation of China (NO. 31210103906), the Chinese National Basic Research Program (2015CB150405), and the European Union's Horizon 2020 Programme for Research \& Innovation under grant agreement n'727217 "ReMIX".

Author's contributions YD and CZ did the literature search, extracted data and conducted the analysis. CZ, YD, YY, DM and WW designed methods for statistical meta-analysis and interpreted results. All authors contributed to formulation of research aims and overall approach, discussed outcomes and approved the submission. CZ, YD, DM and WW wrote the paper.

\section{Compliance with ethical standards}

Conflict of interests The authors declare no conflicts of interests.

\section{References}

Agresti A. 2002. Categorical data analysis. Wiley. 2nd edition. Bedoussac, L., Journet, E., Hauggaard-Nielsen, H., Naudin, C., Corre-Hellou, G., Jensen, E. S., Prieur, L., \& Justes, E. (2015). Ecological principles underlying the increase of productivity achieved by cereal-grain legume intercrops in organic farming. A review. Agronomy Sustainable Development, 35, 911-935.

Bommarco, R., Kleijn, D., \& Potts, S. G. (2013). Ecological intensification: Harnessing ecosystem services for food security. Trends in Ecology and Evolution, 28(4), 230-238.

Borenstein, M., Hedges, L. V., Higgins, J. P. T., \& Rothstein, H. R. (2009). Introduction to meta-analysis. Wiley.

Boudreau, M. A. (2013). Diseases in intercropping systems. Annual Review of Phytopathology, 51, 499-519.

Chakraborty, S., \& Newton, A. C. (2011). Climate change, plant diseases and food security: An overview. Plant Pathology, $60,2-14$.

Chen, Y. X., Zhang, F. S., Tang, L., Zheng, Y., Li, Y. J., Christie, P., \& Li, L. (2007). Wheat powdery mildew and foliar $\mathrm{N}$ concentrations as influenced by $\mathrm{N}$ fertilization and belowground interactions with intercropped faba bean. Plant and Soil, 291, 1-13.

Cong, W. F., Hoffland, E., Li, L., Six, J., Sun, J. H., Bao, X. G., Zhang, F. S., \& van der Werf, W. (2015). Intercropping enhances soil carbon and nitrogen. Global Change Biology, $21,1715-1726$.

Dassou, A. G., \& Tixier, P. (2016). Response of pest control by generalist predators to local-scale plant diversity: A metaanalysis. Ecology and Evolution, 6(4), 1143-1153.

Dordas, C. (2008). Role of nutrients in controlling plant diseases in sustainable agriculture. A review. Agronomy Sustainable Development, 28, 33-46. 
Garrett, K. A., Zúniga, L. N., Roncal, E., Forbes, G. A., Mundt, C. C., Su, Z., \& Nelson, R. J. (2009). Intraspecific functional diversity in hosts and its effect on disease risk across a climatic gradient. Ecological Applications, 19(7), 1868-1883.

Hoffland, E., van Beusichem, M. L., \& Jeger, M. J. (1999). Nitrogen availability and susceptibility of tomato leaves to Botrytis cinerea. Plant and Soil, 210, 263-272.

Hong, Y., Heerink, N. B. M., Jin, S. Q., Berentsen, P. B. M., Zhang, L., \& van der Werf, W. (2017). Intercropping and agroforestry in China; current state and trends. Agriculture, Ecosystems and Environment, 244, 52-61.

Jensen, B., \& Munk, L. (1997). Nitrogen-induced changes in colony density and spore production of Erysiphe graminis f.sp. hordei on seedlings of six spring barley cultivars. Plant Pathology, 46, 191-202.

Jiang, Y. N., Wang, W. X., Xie, Q. J., Liu, N., Wang, D. P., Zhang, X. W., Yang, C., Chen, X. Y., Tang, D. Z., \& Wang, E. T. (2017). Plant transfer lipids to sustain colonization by mutualistic mycorrhizal and parasitic fungi. Science, 356, 1172-1175.

Keesing, F., Belden, L. K., Daszak, P., Dobson, A., Harvell, C., Holt, R. D., Hudson, P., Jolles, A., Jones, K. E., Mitchell, C. E., Myers, S. S., Bogich, T., \& Ostfeld, R. S. (2010). Impacts of biodiversity on the emergence and transmission of infectious diseases. Nature, 468, 647-652.

Li, C. Y., He, X. H., Zhu, S. S., Zhou, H. P., Wang, Y. Y., Li, Y., Yang, J., Fan, J. X., Yang, J. C., Wang, G. B., Long, Y. F., Xu, J. Y., Tang, Y. S., Zhao, G. H., Yang, J. R., Liu, L., Sun, Y., Xie, Y., Wang, H. N., \& Zhu, Y. Y. (2009). Crop diversity for yield increase. PLoS One, 4(11), e8049. https://doi. org/10.1371/journal.pone.0008049.

Lithourgidis, A. S., Dordas, C. A., Damalas, C. A., \& Vlachostergios, D. N. (2011). Annual intercrops: An alternative pathway for sustainable agriculture. Australian Journal of Crop Science, 5, 396-410.

Lv, Z. X., Yu, X. P., Heong, K. L., \& Hu, C. (2005). Effects of nitrogenous fertilization in rice fields on the predatory function of Cytorhinus lividipennis Reuter to Nilaparvata lugens stål. Acta Entomologica Sinica, 48, 48-56 (In Chinese).

Martin-Guay, M.-O., Paquette, A., Dupras, J., \& Rivest, D. (2018). The new green revolution: Sustainable intensification of agriculture by intercropping. Science of the Total Environment, 615, 767-772.

Mitchell, C. E., Reich, P. B., Tilman, D., \& Groth, J. V. (2003). Effects of elevated $\mathrm{CO}_{2}$, nitrogen deposition, and decreased species diversity on foliar fungal plant disease. Global Change Biology, 9, 438-451.

Mundt, C. C. (2002). Use of multiline cultivars and cultivar mixtures for disease management. Annual Review of Phytopathology, 40, 381-410.

Neumann, S., Paveley, N. D., Beed, F. D., \& Sylvester-Bradely, R. (2004). Nitrogen per unit leaf area affects the upper asymptote of Puccinia striiformis f.sp. tritici epidemics in winter wheat. Plant Pathology, 53, 725-732.

Pelzer, E., Bazot, M., Makowski, D., Corre-Hellou, G., Naudin, C., Rifaï, M. A., Baranger, E., Bedoussac, L., Biarnès, V., Boucheny, P., Corrouée, B., Dorvillez, D., Foissy, D., Gaillard, B., Guichar, L., Mansard, M., Omon, B., Prieur, L., Yvergniaus, M., Justes, E., \& Feuffroy, M. (2012). Peawheat intercrops in low-input conditions combine high economic performances and low environmental impacts. European Journal of Agronomy, 40, 39-53.

Philippot, L., Raaijmakers, J. M., Lemanceau, P., \& van der Putten, W. (2013). Going back to the roots: The microbial ecology of the rhizosphere. Nature Reviews Microbiology, 11, 789-799.

Pinheiro, J., \& Bates, D. (2000). Mixed-effects models in S and Splus. New York: Springer.

R Core Team, 2015. R: A language and Environment for Statistical Computing. Foundation for Statistical Computing, Vienna, Austria.

Ren, L. X., Su, S. M., Yang, X. M., Xu, Y. C., Huang, Q. W., \& Shen, Q. R. (2008). Intercropping with aerobic rice suppressed Fusarium wilt in watermelon. Soil Biology and Biochemistry, 40, 834-844.

Royston, P. (1982). An extension of Shapiro and Wilk's $W$ test for normality to large samples. Applied Statstics, 31, 115-124.

Savary, S., Ficke, A., Aubertot, J., \& Hollier, C. (2012). Crop losses due to diseases and their implications for global food production losses and food security. Food Security, 4, 519-537.

Simón, M. R., Cordo, C. A., Perelló, A. E., \& Struik, P. C. (2003). Influence of nitrogen supply on the susceptibility of wheat to Septoria tritici. Journal of Phytopathology, 151, 283-289.

Skelsey, P., Rossing, W. A. H., Kessel, G. J. T., Powell, J., \& van der Werf, W. (2005). Influence of host diversity on development of epidemics: An evaluation and elaboration of mixture theory. Phytopathology, 95, 328-338.

Snoeijers, S. S., Pérez-García, A., Joosten, H. A. J., \& De Wit, P. J. G. M. (2000). The effect of nitrogen on disease development and gene expression in bacterial and fungal plant pathogens. European Journal of Plant Pathology, 106, 493-506.

Strehmel, N., Bottcher, C., Schmidt, S., \& Scheel, D. (2014). Profiling of secondary metabolites in root exudates of Arabidopsis thaliana. Phytochemistry, 108, 35-46.

Tilman, D., Cassman, K. G., Matson, P. A., Naylor, R., \& Polasky, S. (2002). Agricultural sustainability and intensive production practices. Nature, 418, 671-677.

Tooker, J. F., \& Frank, S. D. (2012). Genotypically diverse cultivar mixtures for insect pest management and increased crop yields. Journal of Applied Ecology, 49, 974-985.

Trenbath, B. R. (1993). Intercropping-bases of productivity intercropping for the management of pests and diseases. Field Crops Research, 34, 381-405.

Turnbull, L. A., \& Hector, A. (2010). How to get even with pests. Nature, 466, 36-37.

van Dam, N. M., \& Bouwmeester, H. (2016). Metabolimics in the rhizosphere: Tapping into belowground chemical communication. Trends in Plant Science, 21, 256-265.

Vandermeer, J. (1998). Maximizing crop yield in alley crops. Agroforestry Systems, 40, 199-206.

Weston, L. A., \& Mathesius, U. (2013). Flavonoids: Their structure, biosynthesis and role in the rhizosphere, including allelopathy. Journal of Chemical Ecology, 39, 283-293.

Wiik, L. (2009). Yield and disease control in winter wheat in southern Sweden during 1977-2005. Crop Protection, 28, 82-89.

Willey, R. W. (1985). Evaluation and presentation of intercropping advantages. Experimental Agriculture, 21, 119-133.

Xu, W. H., Liu, D., Wu, F. Z., \& Liu, S. W. (2015). Root exudates of wheat are involved in suppression of Fusarium wilt in 
watermelon in watermelon-wheat companion cropping. European Journal of Plant Pathology, 141, 209-216.

Yu, Y., Stomph, T. J., Makowski, D., \& van der Werf, W. (2015). Temporal niche differentiation increases the land equivalent ratio of annual intercrops: A meta-analysis. Field Crops Research, 184, 133-144.

Yu, Y., Stomph, T., Makowski, D., Zhang, L. Z., \& van der Werf, W. (2016). A meta-analysis of relative crop yields in cereal/ legume mixtures suggests options for management. Field Crops Research, 198, 269-279.

Zadoks, J. C., \& Schein, R. D. (1979). Epidemiology and plant disease management (p. 427). Oxford: Oxford University Press.

Zhang, F. S., \& Li, L. (2003). Using competitive and facilitative interactions in intercropping systems enhances crop productivity and nutrient-use efficiency. Plant and Soil, 248, 305-312.
Zhang, S., Luo, H. G., Zhang, Q. D., Xu, Y. Y., Zou, C. H., Guo, M. L., He, S. M., Fang, X. W., Zhang, J. X., \& Chen, Q. Z. (2008). Effects of nitrogen and potassium fertilizer applications on yield and occurrence of major diseases and insect pests of rice. Journal of Huazhong Agricultural University, 27, 732-735 (In Chinese).

Zhu, Y. Y., Chen, H. R., Fan, J. H., Wang, Y. Y., Li, Y., Chen, J. B., Fan, J. X., Yang, S. S., Hu, L. P., Leung, H., Mew, T. W., Teng, P. S., Wang, Z. H., \& Mundt, C. C. (2000). Genetic diversity and disease control in rice. Nature, 406, 718-722.

Zuur AF, Ieno EN, Walter NJ, Saveliev AA \& Smith GM. 2009. Mixed effects models and extensions in ecology with R. Springer, 574 pp. 